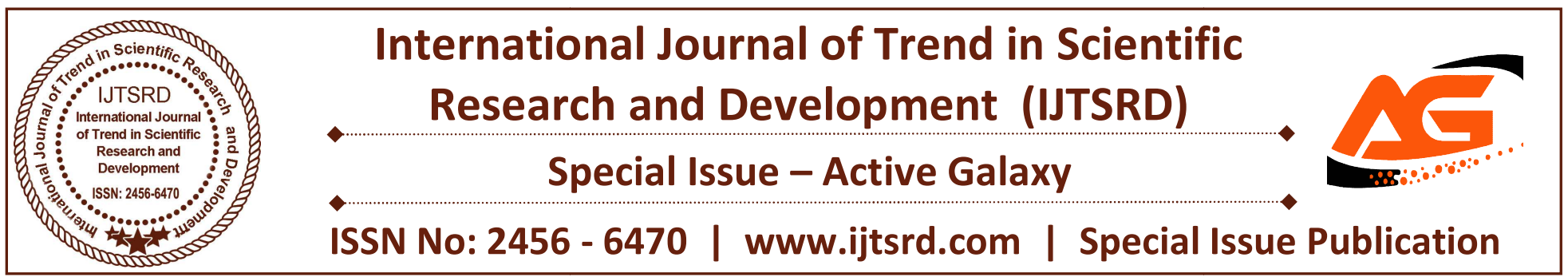

\title{
Online Voting Using Biometric
}

\author{
Dr. S. Hemalatha ${ }^{1}$, Ms. M. Gowthami ${ }^{2}$, V. Karthi ${ }^{3}$ \\ ${ }^{1}$ Professor, ${ }^{2}$ Assistant Professor, ${ }^{3}$ Student \\ ${ }^{1,2}$ Department of Computer Science and Engineering, ${ }^{3}$ Master of Computer Application Department \\ Veltech Hightech Dr Rangarajan Dr Sakunthala Engineering College \\ Affiliated to Anna University, Chennai, Tamil Nadu, India
}

\begin{abstract}
The problem of voting system is still critical in terms of safety and security. This paper deals with the webbased voting system using fingerprint and Aadhar card in order to provide a high performance with high security to the voting system. The Online voting using system allows the voters login to scan their fingerprint, which is then matched with an already saved image within a database that is retrieved from Aadhar card database to check the voter is eligible or not for casting the vote the verification done by the hall supervisor. The users must login by Aadhar card details based, then the voter login success full, the page will open and shows the candidate details then click on his/her favorable candidates to cast their votes. This will increase the voting percentage in India and reduces the cost of contributing the elections. By using biometric fingerprint it provides high level security and reliability of every one.
\end{abstract}

Keywords: fingerprint, Aadhar card, security and reliability.

\section{INTRODUCTION}

The online voting using biometric system overcomes the problems of existing voting system. It provides the easy way of conducting the election whenever, because every data can be computerized no paper works needed. It gives the high level security to the election commission. It is easy to implement in the process. Voter can cast their votes from their voting booths only, in highly secured way. That makes voting a fearless of violence and that increases the percentage of voting. The voter need not to bring voter ID card and any slips, they only bring the Aadhar card only enough. Then the voter login by the biometric finger print way to casting their vote from their favorable candidate. When the voter could finishing their vote the page automatically logout, and the data stored in the election commission data base. It provides the high level security of the voting system, and ensures the voters reliability.

\section{EXISTING SYSTEM:}

The existing system of election is running manually. The elector must visit to booths to vote a candidate therefore there's wastage of your time. The elector must manually register into the elector list. Conjointly vote enumeration must be done manually. All the data of the elector or candidate is to be filling in manually. Elector should be gift in his/her body to provide his/her Vote. There are electronic balloting machines used that takes additional price .voting system antecedently being employed by the government could be a paper based mostly system, within which the elector merely picks up ballots sheets from electoral officers.

Paper-based voting: The Electors gets a blank ballot and use a pen or a marker to point he need to vote that candidate. Hand-counted ballots could be a time and labor overwhelming method, however it's straightforward to manufacture paper ballots and also the ballots is maintained for collateral, this kind continues to be the foremost common thanks to vote. This type of mechanical device will count up the ballots mechanically. As a result of its interface isn't 
easy enough, giving some coaching to voters is important.

Direct recording electronic balloting machine: this kind, which is abbreviated to DRE, integrates with keyboard; bit screen, or buttons for the elector press to poll. A number of them lay in balloting records and enumeration the vote is extremely quickly. However the opposite DRE while not keep balloting records are doubted concerning its accuracy.

Punch card: The elector uses hole-punch to punch a hole on the blank ballot. It will count votes mechanically, however if the voter's perforation is incomplete, the result's in all probability determined.

\section{PROPOSED SYSTEM:}

The proposed biometric online voting system provides the secure voting and reliability of the voters on the election commission. It allows particular voter to cast the vote online and update the database in the server. Biometric online voting system uses aadhar card to retrieve the complete details about the voter. The proposed online voting biometric system is to avoiding the fake votes and some malpractices in the casting votes. The architecture design is able to understanding the process of the online voting using biometric system. In this mechanism to avoiding the many process in the election commission, because the mostly paper work using in the election commission to survey the eligible voters. So it consumes the lot of manual works to the election commission. Then the electronic voting machine contains the many issues itself. so the all problems overcomes here to providing the secured and reliable voting system for the voters. The election commission admin only add the voters and remove from the election commission data base. When the election date is announced then the candidate registered in the election commission page. In this system gives many advantages to the voters, when they going to the election booth they don't bring the voter ID card and any slips they only bring their Aadhar card is enough. All Indians having a unique identification of Aadhar card, it contains the all details of the particular person. So we can get the Aadhar card details from the government. The Aadhar card contains the name, age, address and biometric information of the voter. The process of online voting system a voter can enter the election booth and biometric finger print verification by the booth supervisor check the age limitation, already voted or not and correct voter or not from the election commission local data base. The verification is success full then the voter go to next system to login by the biometric finger print if matched the aadhar card details it automatically login and show the logos of the candidates then the voters could cast their votes to the favorable candidates, The voter can vote once when the voter touch the specific logo then the page automatically logout and the data stored in the election commission data base. Then the election commission easy to count the votes and announcing the election result on the day itself. The voters can cast their vote to the election booths only, can't vote by the mobile because its main drawback is many people's not having the mobile phones then lot of villages not yet connected by the networks. Government able to give the all kind resources providing in this voting system .so it consuming the less cost of conducting the elections and providing the reliability of the voters.

\section{FUNCTIONAL MODELS:}

\section{ADMINISTRATION MODULE}

The election commission is the administrative in the online voting system. The all voters details and candidates details is stored in the election commission data base, the users can't change any modification in their profile without permission of the election commission. Over all process monitoring by the election commission administrative.

\section{VERIFICATION MOUDLE}

The verification module to verify the voter age eligibility and biometric authentication for if the voter is eligible to cast the vote, It could be done by the booth supervisor.

\section{CLIENT MODULE}

The voter login by the biometric finger print verification, if the finger print matches with the aadhar card information then the voter could cast their vote to the favorable candidate at once then the page will automatically logout. 


\section{System Design}

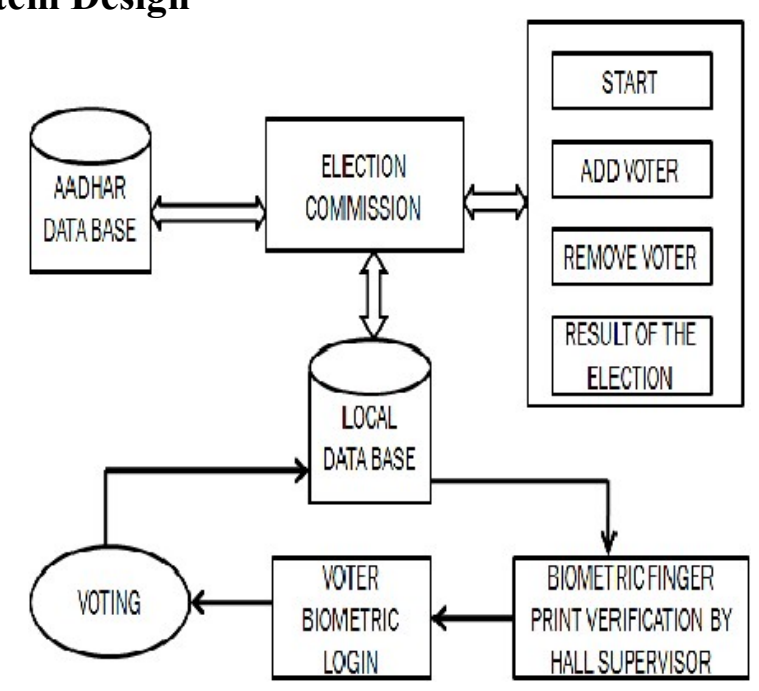

\section{SYSTEM IMPLEMENTATION:}

The online voting system provide a mechanism to voter login by the biometric finger print, if matches then only a voter could cast their vote. The biometric system provides a security to the voter and avoiding the unauthorized access.

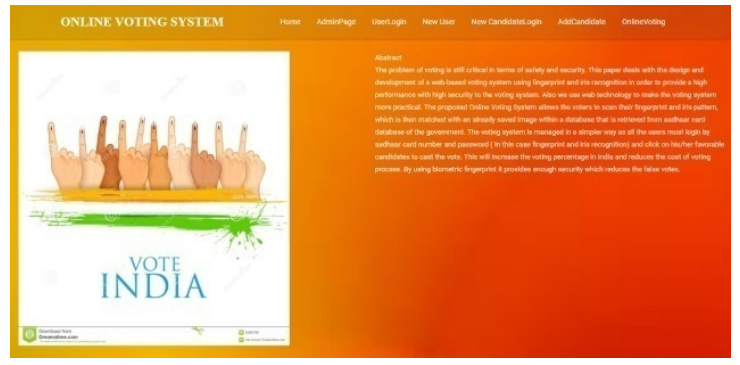

1.This is the overall election commission page.

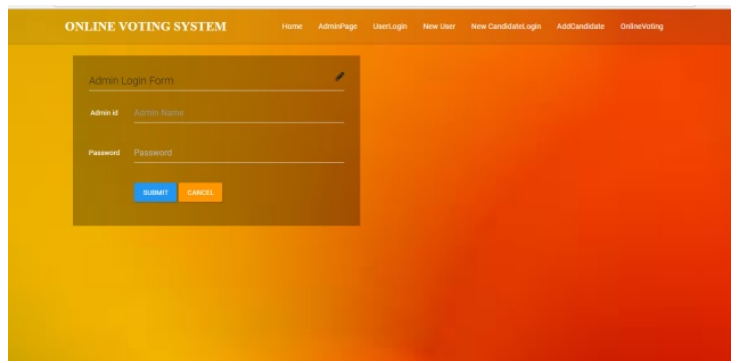

2.This is election commission admin login page.

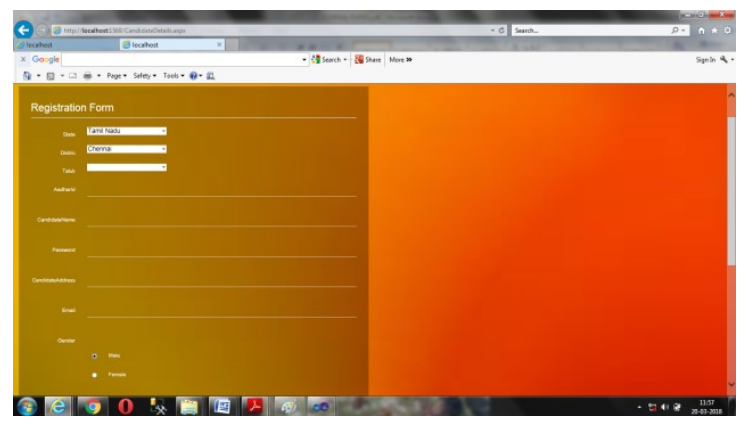

3.This is a new candidate registration form.

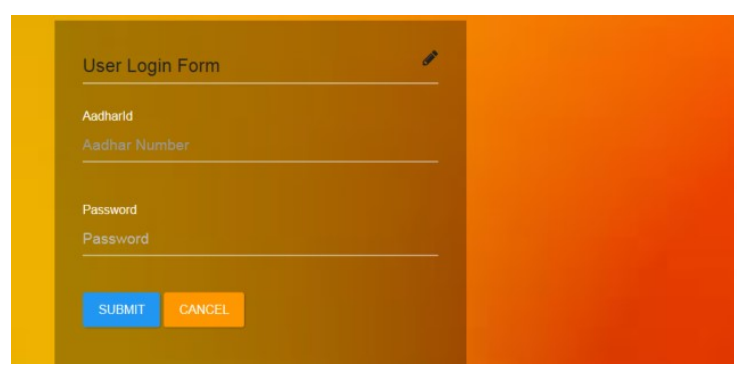

4. The voter verification page.

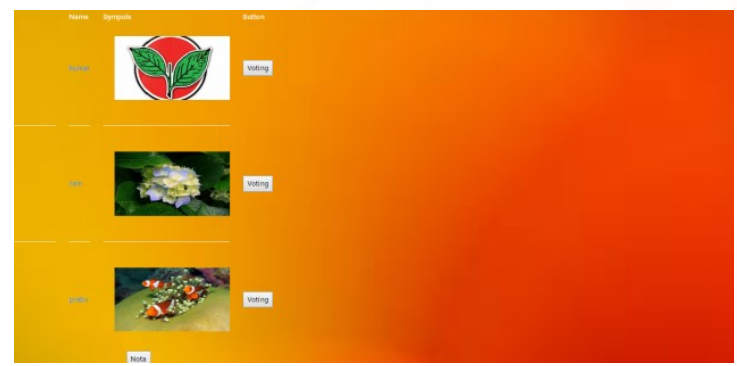

5.The voter success full login.

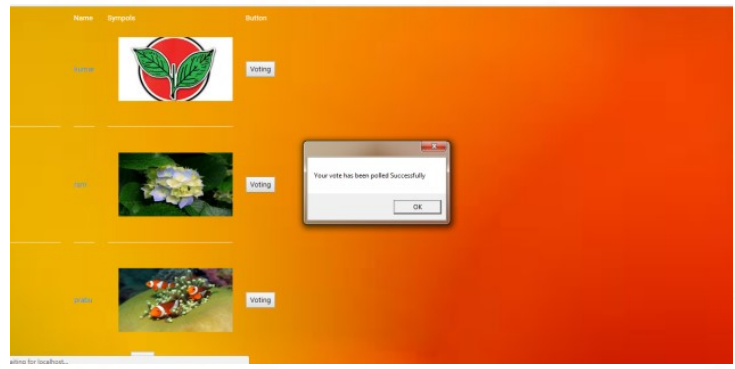

6. Voter they casting their vote.

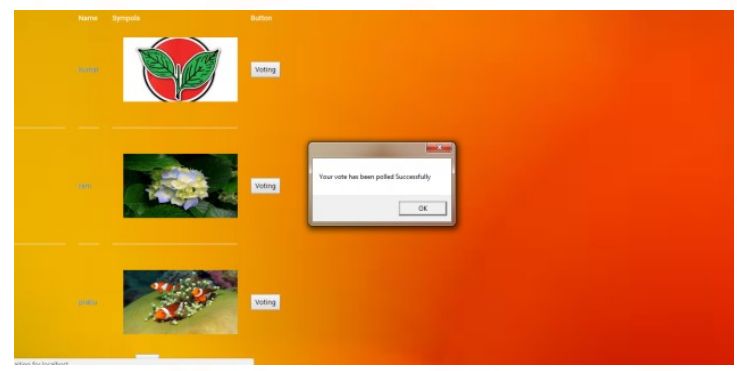

7.Voter successfully voted and logout.

\section{CONCLUSION:}

An online voting biometric system provides a many features than the electronic voting machine. The online voting system to avoiding the duplicate voters to vote, a vote could be vote by the particular voter only, the person can't vote for the others. When the voters casting their votes it automatically stores in the election commission server, so the result could be announce on the day itself. In this system avoiding the EVM machines it requires only the computer, finger print equipment, network connection and touch screen monitor. So it provides the huge security to the 


\section{Special Issue - Active Galaxy}

election commission they easily conducting the elections whenever. It provides the security and reliability to the voters, the fake voters could easily find by the election commission. In this system avoiding the conflicts, it increases the voting percentage.

\section{REFERENCES}

1. Benaloh, J.\& Tuinstra, D. (1994) "Receipt-free Secret-Ballot Elections", In Proceedings of the 26th ACM Symposium on Theory of Computing (STOC'94), Montreal, Canada.

2. APPENDIX 2J, Experience of electronics voting overseas. THE POLICY INSTITUTE,TRINITY COLLEGE DUBLIN.Dr.Kenneth Benoit ,Department of Political Secience TCD.

3. Brennock, M. (2004) Cabinet to press ahead on evoting in EU and local polls. The Irish Times.

4. California Secretary of State Ad Hoc Touch screen Voting Task Force Report

5. Caltech-MIT. (2001) Voting: what is, what could be. Cal Tech-MIT Voting technology Project Report

6. Cetinkaya, O. \&Cetinkaya, D. (2007) "Towards Secure E-Elections in Turkey: Requirements and Principles".

7. Chaum, D. (1981) "Untraceable Electronic Mail, Return Addresses, and Digital Pseudonym.
8. Chaum, D. (1982) "Blind Signatures for Untraceable Payments".

9. Chaum, David (2000) Secret-Ballot Receipts and Transparent Integrity.

10. Cranor, L. \&Cytron, R. (1997) "Sensus: A Security-Conscious Electronic Polling System for the Internet".

11. Fujioka, A., Okamoto, T. and Ohta, K. (1992) "A Practical Secret Voting Scheme for Large Scale Elections".

12. Gritzalis D, editor. (2002) Secure electronic voting. Advances in information security.

13. Hoffer, J. A., et al (2002). Modern Systems Analysis \& Design3rd edition, Prentice Hall, Upper Saddle River, NJ.

14. Jefferson, D.R., Rubin, A.D., Simons, B., and Wagner, D. (2004) A "Security Analysis of the Secure Electronic Registration and Voting Experiment (SERVE)"

15. Kazi, M.A.F. (2003): Realist Evaluation in Practice, Sage, London.

16. Nishigandha $C 1$, Nikhil P2, Suman P3, Vinayak G4, Prof. Vishal D5 "Online Voting System Using Aadhar Card and Biometric"

17. Prof. JadhavAbhijit D., Ambavane Pooja R., Patil Mrunalini A. Shewale Kalyani G., Vishwasrao Shyama P. "Online Voting System Based On Biometrics Using Adhar Card Data" 